\title{
CO-PRODUÇÃO DE LIPASE E BIOSSURFACTANTE EM ESTADO SÓLIDO PARA UTILIZAÇÃO EM BIORREMEDIAÇÃO DE ÓLEOS VEGETAIS E HIDROCARBONETOS
}

\author{
Vilásia Guimarães Martins, Susana Juliano Kalil e Jorge Alberto Vieira Costa* \\ Escola de Química e Alimentos, Universidade Federal do Rio Grande, CP 474, 96201-900,Rio Grande - RS, Brasil
}

Recebido em 4/7/07; aceito em 12/6/08; publicado na web em 5/11/08

\begin{abstract}
LIPASES AND BIOSURFACTANT PRODUCTION BY SOLID STATE FERMENTATION FOR UTILIZATION IN BIOREMEDIATION OF VEGETABLE OILS AND HYDROCARBONS. Recently lipases have been increasing in prominence due to its wide industrial application. The lipase production can be influenced by different variables such as the producing microorganism, carbon sources, aeration and agitation conditions, inductor type and the geometry of the reactor. Biosurfactants are composites of surface active produced by microbial cells which reduce superficial and interfacial tensions. The objective of this study was to verify the influence of different process variables in the lipase production during a fermentative process. The results showed that the concomitant production of lipases and biosurfactant was possible in different cultivation conditions.
\end{abstract}

Keywords: Aspergillus fumigatus; Phialemonium sp.; carbon sources.

\section{INTRODUÇÃO}

As lipases podem ser de origem animal (pancreática, hepática e gástrica), microbiana (bactérias e fungos) e vegetal. A principal função biológica da lipase (triacilglicerol acil hidrolases, E.C.3.1.1.3) é catalisar a hidrólise de longas cadeias de triacilglicerídeos. Ao contrário de muitas outras enzimas, as lipases demonstram níveis consideráveis de atividade e estabilidade em ambientes não-aquosos, o que facilita a catálise de muitas reações, tais como esterificação e transesterificação. ${ }^{1}$

A fermentação em estado sólido é uma tecnologia adequada à produção de enzimas, uma vez que este processo pode ser realizado in situ e rejeitos industriais podem ser empregados como fonte de nutrientes para o processo fermentativo. ${ }^{2}$ Além disso, pesquisas com fermentação em estado sólido têm apresentado maiores produções de lipases, quando comparada com a fermentação submersa; esta vantagem é atribuída à alta taxa de crescimento da biomassa e à baixa atividade proteolítica. ${ }^{1}$

A produção de lipases pode ser influenciada por diferentes variáveis, como o microrganismo produtor da enzima, as fontes de carbono e nitrogênio, a concentração de oxigênio dissolvido, a composição, temperatura e pH do meio, as condições de aeração e agitação e até mesmo a geometria do biorreator. ${ }^{3}$ Lipases são produzidas por um grande número de microrganismos, incluindo bactérias, fungos e leveduras. Os fungos são os preferidos como produtores industriais de lipases porque as enzimas produzidas por estes normalmente são extracelulares, o que facilita a extração do meio fermentado. $\mathrm{Na}$ produção de lipases a partir de fungos, os substratos lipídicos atuam como indutores em muitas espécies, nos quais as lipases são produzidas constitutivamente. ${ }^{4,5}$

Atualmente, muitas fontes de carbono têm sido estudadas, pois existe um interesse expressivo em otimizar estas fontes durante a produção de lipase e também em encontrar alternativas economicamente mais atrativas. ${ }^{6-8}$

As lipases têm encontrado aplicações promissoras em uma variedade de segmentos biotecnológicos, como em indústrias de alimentos, ${ }^{9,10}$ de detergentes, ${ }^{11,12}$ na biotransformação de óleos e

\footnotetext{
*e-mail: jorgealbertovc@ terra.com.br
}

gorduras, ${ }^{13}$ obtenção de fármacos, ${ }^{14}$ tratamento biológico de águas residuárias, ${ }^{2,15}$ aceleração da biodegradação de polímeros. ${ }^{16}$ Hidrocarbonetos de petróleo têm sido mencionados como substratos potenciais para a produção microbiana de várias enzimas comerciais importantes e metabólitos secundários. ${ }^{17}$

Os biossurfactantes são moléculas anfipáticas que contêm partes hidrofílicas e hidrofóbicas e atuam em interfaces as quais possuem polaridades diferentes, tais como água-óleo, óleo-água, ar-água, entre outras. ${ }^{18}$ Para produzir biossurfactante, substratos de alto custo são dispensados, podendo ser utilizados para o metabolismo celular, resíduos oleosos de indústrias de alimentos, viabilizando economicamente o processo. Makkar e Cameotra ${ }^{19}$ citam que os resíduos agroindustriais são os substratos mais utilizados no processo de fermentação em estado sólido, dentre eles, polpa de café, farelo de cereais, palhas de arroz e trigo, bagaço de cana, cascas de frutas processadas, batata, farinha de cereais, mandioca, entre outros. A utilização destes substratos contribui para a redução de custos, uma vez que o meio de cultivo representa aproximadamente $50 \%$ do valor do produto final. ${ }^{20}$

Considerando a extraordinária diversidade microbiana e a importância dos fungos como produtores de enzimas, justifica-se a busca de novos biocatalisadores com características especiais e passíveis de aplicação em biocatálise. Com base nestes aspectos, o objetivo deste trabalho foi avaliar a produção de lipases por fermentação em estado sólido, realizada em biorreatores de colunas e em erlenmeyers, durante a produção de biossurfactante.

\section{PARTE EXPERIMENTAL}

\section{Microrganismos}

Os fungos filamentosos utilizados foram Aspergillus fumigatus e Phialemonium sp.. Estes foram isolados de um local contaminado por hidrocarbonetos situado no estado de São Paulo (Brasil). As cepas foram cedidas pelo Laboratório de Microbiologia de Alimentos, Faculdade de Engenharia de Alimentos, Universidade Estadual de Campinas (FEA/UNICAMP). Os microrganismos foram mantidos em ágar batata-dextrose (PDA) e 1\% de glicerina a temperatura de $4{ }^{\circ} \mathrm{C}$. 


\section{Preparo do inóculo para a fermentação}

A propagação dos fungos foi realizada em frascos de Roux, sendo estes incubados a $30^{\circ} \mathrm{C}$ em meio PDA (Acumedia Manufacturers, USA) durante um período de 7 dias. Os esporos foram suspensos em 0,2\% Tween 80 (v/v). A contagem de esporos para o fungo Aspergillus fumigatus foi realizada em câmara de Neubauer e para o fungo Phialemonium sp. foi através de plaqueamento em ágar dicloran rosa de bengala cloranfenicol (Acumedia Manufacturers, USA), incubado a $25^{\circ} \mathrm{C}$ por 3 dias.

\section{Fermentação em estado sólido}

As fermentações foram realizadas em biorreatores de colunas, com $50 \mathrm{~mm}$ de diâmetro e $250 \mathrm{~mm}$ de altura e em erlenmeyers de $1000 \mathrm{~mL}$, utilizando os fungos Aspergillus fumigatus e Phialemonium sp.. O farelo desengordurado e a casca de arroz foram cedidos pela Indústria Riograndense de Óleos Vegetais Ltda situada em Pelotas, Rio Grande do Sul, Brasil. O óleo de soja e o óleo diesel foram adquiridos no comércio local.

Foram avaliados dois meios fermentativos, o suporte complexo, composto por casca e farelo de arroz desengordurado. O farelo foi moído em moinho de facas com malhas de 1 e $0,5 \mathrm{~mm}$. Após a moagem o farelo foi peneirado, e então recolhidas as partículas retidas nas peneiras de 0,420 e $0,500 \mathrm{~mm}$. O segundo meio fermentativo, o suporte sintético, foi constituído de um inerte, que foi a casca de arroz. A casca de arroz utilizada nos dois substratos não foi triturada. Aos substratos, foi adicionada uma solução de micronutrientes com a seguinte composição $\left(\mathrm{g} \mathrm{L}^{-1}\right)$ : $\mathrm{MgSO}_{4} .7 \mathrm{H}_{2} \mathrm{O}(0,5) ; \mathrm{NaNO}_{3}(3)$; KH${ }_{2} \mathrm{PO}_{4}(1)$, da indústria Synth, Brasil; extrato de levedura (1) e peptona $(0,3)$, da indústria Vetec, Brasil, todos com grau de pureza analítica. Foram avaliadas duas fontes de carbono adicionais, óleo diesel e óleo de soja fornecidos na proporção de $1 \%$; também foram avaliados os meios sem fonte de carbono adicional. A fermentação teve a duração de 120 h. Nos biorreatores de colunas, foi avaliada a influência da aeração na produção de lipase, sendo as taxas de aeração estudadas de 60 e $120 \mathrm{~mL} \mathrm{~g}^{-1} \mathrm{~h}^{-1} .^{21}$

As condições físico-químicas utilizadas nas fermentações foram umidade $50 \%$, temperatura de fermentação $30^{\circ} \mathrm{C}$, concentração inicial de esporos 4 x $10^{6}$ esporos $\mathrm{g}^{-1}$ e $\mathrm{pH} 4,5$. $^{22}$ Todas as determinações analíticas descritas a seguir foram realizadas em triplicata e a cada $24 \mathrm{~h}$.

\section{Determinação de umidade}

$\mathrm{O}$ teor de umidade das amostras fermentadas foi determinado segundo metodologia da $\mathrm{AOAC},{ }^{23}$ baseada na perda de peso após a secagem em estufa a $105^{\circ} \mathrm{C}$ por cerca de 3 a $5 \mathrm{~h}$.

\section{Determinação de pH}

A determinação do $\mathrm{pH}$ das amostras foi realizada diretamente em pHmetro digital da marca Quimis HI 8314, membrane pHmeter, utilizando os padrões $\mathrm{pH} 4$ e 7 da marca Quimis para a calibração.

\section{Determinação da atividade lipolítica}

$\mathrm{Na}$ determinação da atividade lipolítica foi adotado o método utilizando goma arábica. ${ }^{24} \mathrm{O}$ método é baseado na titulação com $\mathrm{NaOH} 0,05 \mathrm{~N}$ dos ácidos graxos liberados pela ação da enzima lipase, presente no extrato enzimático da fermentação, sobre os triacilglicerídeos do azeite de oliva (adquirido no comércio local) emulsionados em goma arábica (Synth, Brasil) por $30 \mathrm{~min}$ a $37^{\circ} \mathrm{C}$. Uma unidade de atividade de lipase foi definida como a quantidade de enzima que libera $1 \mu \mathrm{mol}$ de ácido graxo por min. A atividade lipolítica foi determinada a cada $24 \mathrm{~h}$, juntamente com um ensaio branco, que consistiu na aplicação do método nas mesmas condições executadas para as análises lipolíticas, porém sem a adição da amostra.

\section{Extração do biossurfactante}

A extração do biossurfactante do meio fermentativo foi realizada com água aquecida a $90{ }^{\circ} \mathrm{C}$, na proporção 1:3 (uma parte de meio para três partes de água). Após a adição do solvente, a amostra foi submetida à agitação em Shaker B, Braun Certomat BS-1 a 160 rpm e $50{ }^{\circ} \mathrm{C}$ por $30 \mathrm{~min}$. A seguir, a amostra foi filtrada a vácuo e o extrato utilizado para a avaliação da atividade emulsificante.

\section{Atividade emulsificante}

A atividade emulsificante do meio foi testada utilizando $3,5 \mathrm{~mL}$ de extrato e $2 \mathrm{~mL}$ de óleo de soja. Esta mistura foi agitada em agitador vortex a $700 \mathrm{rpm}$ por $1 \mathrm{~min}$. Após $60 \mathrm{~min}$ de repouso foi lida a absorbância do meio emulsificado em espectrofotômetro a $610 \mathrm{~nm}^{25} \mathrm{e}$ ao final de $24 \mathrm{~h}$, a relação entre a altura total de óleo e a altura de óleo emulsificado, ${ }^{26}$ sendo então determinados os valores de atividades emulsificantes, definidas pelas Equações 1 e 2:

$$
\begin{aligned}
& A E_{w / o}=\frac{E^{*} D}{[m(1-U)]} \\
& A E_{o / w}=\frac{A b s^{*} D}{[m(1-U)]}
\end{aligned}
$$

onde, $\mathrm{AE}_{\mathrm{w} / \mathrm{o}}$ é a atividade emulsificante água em óleo $\left(\mathrm{UE} \mathrm{g}^{-1}\right) ; \mathrm{AE}_{\mathrm{o} / \mathrm{w}}$, a atividade emulsificante óleo em água $\left(\mathrm{UE} \mathrm{g}^{-1}\right)$; E, a relação centesimal entre a altura da emulsão e a altura total; Abs, a absorbância da suspensão do óleo em água; D, a diluição da amostra em água; m, a massa da amostra úmida (g) e $\mathrm{U}$, a umidade do meio fermentado.

$A$ atividade emulsificante água em óleo $\left(\mathrm{AE}_{\mathrm{w} / 0}\right)$ foi definida como a massa de farelo fermentado necessária para manter estável por 24 h a emulsão de $1 \%$ da fase hidrófoba, expressa em Unidade Emulsificante por $\mathrm{g}$ de meio fermentado ( $\mathrm{UE} \mathrm{g}^{-1}$ ). A atividade emulsificante óleo em água $\left(\mathrm{AE}_{\mathrm{o} / \mathrm{w}}\right)$ foi definida como a massa de farelo fermentado necessária para aumentar a absorbância da emulsão em 1 unidade a $610 \mathrm{~nm}$, quando comparada com o branco, expressa em Unidade Emulsificante por $\mathrm{g}$ de meio fermentado $\left(\mathrm{UE} \mathrm{g}^{-1}\right)$.

\section{Planejamento experimental e análise estatística}

Foram aplicados dois planejamentos experimentais fatoriais mistos, sendo um $2^{2} \times 3$ para os erlenmeyers e um $2^{3} \times 3$ para os biorreatores de coluna. As variáveis estudadas foram os meios, a aeração, os fungos e as fontes de carbono utilizadas. Na Tabela 1 estão apresentados os fatores que foram avaliados, com as respectivas variações.

\section{RESULTADOS E DISCUSSÃO}

Na Tabela 2 está descrito o planejamento experimental misto $2^{3} \times 3$ utilizado para avaliar a produção de lipase nos biorreatores de coluna. A análise do planejamento foi realizada para um nível de significância de 5\%; para isto, foram utilizados os resultados de atividade lipolítica máxima para cada experimento.

A umidade do meio contendo farelo e casca de arroz permaneceu estável durante todo o período da fermentação, ficando em $50 \pm 3 \%$. Porém, o meio que continha apenas casca de arroz apresentou altera- 
Tabela 1. Fatores avaliados e os níveis de variação para os experimentos realizados

\begin{tabular}{lccc}
\hline Variáveis & \multicolumn{3}{c}{ Níveis } \\
\hline Fungo & Aspergillus & 0 & +1 \\
Meio Fermentativo & fumigatus & - & Phialemonium \\
*Aeração & $60 \mathrm{~mL} \mathrm{~g}^{-1} \mathrm{~h}^{-1}$ & - & $\begin{array}{c}\text { sp. } \\
\text { complexo }\end{array}$ \\
Fonte de Carbono & óleo de soja & óleo diesel & $\begin{array}{c}\text { sem fonte adi- } \\
\text { cional }\end{array}$ \\
\hline
\end{tabular}

*Variável estudada somente nos biorreatores de coluna

Tabela 2. Resultado do planejamento experimental misto $2^{3} \times 3$ para a atividade lipolítica nos biorreatores de coluna

\begin{tabular}{|c|c|c|c|c|c|}
\hline Experimentos & $\mathrm{X}_{1}$ & $X_{2}$ & $X_{3}$ & $\mathrm{X}_{4}$ & $\begin{array}{c}\text { Atividade } \\
\text { Lipolítica }\left(\mathrm{U} \mathrm{g}^{-1}\right)\end{array}$ \\
\hline 1 & -1 & -1 & -1 & -1 & 44,68 \\
\hline 2 & 1 & -1 & -1 & -1 & 49,75 \\
\hline 3 & -1 & 1 & -1 & -1 & 119,46 \\
\hline 4 & 1 & 1 & -1 & -1 & 129,50 \\
\hline 5 & -1 & -1 & 1 & -1 & 37,97 \\
\hline 6 & 1 & -1 & 1 & -1 & 40,09 \\
\hline 7 & -1 & 1 & 1 & -1 & 107,16 \\
\hline 8 & 1 & 1 & 1 & -1 & 99,35 \\
\hline 9 & -1 & -1 & -1 & 0 & 58,25 \\
\hline 10 & 1 & -1 & -1 & 0 & 49,24 \\
\hline 11 & -1 & 1 & -1 & 0 & 84,98 \\
\hline 12 & 1 & 1 & -1 & 0 & 59,45 \\
\hline 13 & -1 & -1 & 1 & 0 & 41,60 \\
\hline 14 & 1 & -1 & 1 & 0 & 47,40 \\
\hline 15 & -1 & 1 & 1 & 0 & 94,88 \\
\hline 16 & 1 & 1 & 1 & 0 & 56,17 \\
\hline 17 & -1 & -1 & -1 & 1 & 18,61 \\
\hline 18 & 1 & -1 & -1 & 1 & 22,44 \\
\hline 19 & -1 & 1 & -1 & 1 & 105,34 \\
\hline 20 & 1 & 1 & -1 & 1 & 54,92 \\
\hline 21 & -1 & -1 & 1 & 1 & 20,33 \\
\hline 22 & 1 & -1 & 1 & 1 & 24,31 \\
\hline 23 & -1 & 1 & 1 & 1 & 98,35 \\
\hline 24 & 1 & 1 & 1 & 1 & 57,07 \\
\hline
\end{tabular}

$\mathrm{X}_{1}=$ fungo; $\mathrm{X}_{2}=$ meio fermentativo; $\mathrm{X}_{3}=$ aeração; $\mathrm{X}_{4}=$ fonte de carbono.

ções na umidade em torno de $96 \mathrm{~h}$ de fermentação, isto provavelmente se deve à dificuldade que a casca tem de absorver água. Em alguns ensaios a umidade chegou em torno de $20 \%$. Segundo Pokorny et al.,${ }^{27} \mathrm{o}$ nível de umidade na fermentação em estado sólido tem um grande impacto sobre as propriedades físicas do substrato sólido. Altos índices de umidade podem causar decréscimo da porosidade e também diminuem a transferência de oxigênio. Por outro lado, a baixa umidade diminui a solubilidade do substrato sólido, o grau de inchamento das partículas e produz uma alta tensão superficial. ${ }^{28} \mathrm{O}$ $\mathrm{pH}$ permaneceu estável durante o processo fermentativo em ambos os meios, ficando em torno de 5,0 $\pm 0,5$.

Ao relacionar a produção de biossurfactante com a de lipase, foi verificado que a produção de lipase provavelmente não interferiu na produção de biossurfactante, pois os valores encontrados não demonstraram uma tendência de aumento ou decréscimo das atividades emulsificantes. As atividades lipolíticas encontradas no suporte inerte apresentaram resultados muito inferiores aos encontrados para o suporte complexo, porém foram encontradas atividades emulsificantes água/óleo e óleo/água altas em ambos suportes. Este é mais um indicativo de que a quantidade de lipase no meio não interferiu na produção de biossurfactante.

A atividade lipolítica máxima encontrada para o fungo Phialemonium sp. foi $129,50 \mathrm{U} \mathrm{g}^{-1}$, quando utilizado o suporte complexo, aeração de $60 \mathrm{~mL} \mathrm{~g}^{-1} \mathrm{~h}^{-1} \mathrm{e}$ óleo de soja como fonte de carbono adicional; para este mesmo experimento foi encontrado 7,67 $\mathrm{UE} \mathrm{g}^{-1} \mathrm{de}$ atividade emulsificante óleo/água e 5,07 UE g-1 para água/óleo. Os máximos observados de atividades emulsificantes para este fungo foram de 12,21 UE g ${ }^{-1}$ para óleo/água e 6,11 UE g-1 para água/óleo.

Para o fungo Aspergillus fumigatus a atividade lipolítica máxima foi de $119,46 \mathrm{U} \mathrm{g}^{-1}$, quando utilizado o suporte complexo, aeração de $60 \mathrm{~mL} \mathrm{~g}^{-1} \mathrm{~h}^{-1}$ e óleo de soja como fonte de carbono adicional. Para este experimento foi observado $9,10 \mathrm{UE} \mathrm{g}^{-1}$ de atividade emulsificante óleo/água e 7,36 UE g-1 para água/óleo. Os máximos observados para este fungo foram de 11,54 $\mathrm{UE} \mathrm{g}^{-1}$ para a atividade emulsificante óleo/ água e 7,36 UE g-1 para água/óleo.

A Figura 1 mostra a cinética da produção de lipase para cada uma das fontes de carbono estudadas durante o período de fermentação.

Foi observado que para o óleo diesel, o fungo Aspergillus fumigatus, a partir do suporte complexo, apresentou os melhores resultados, sendo que com aeração de $120 \mathrm{~mL} \mathrm{~g}^{-1} \mathrm{~h}^{-1}$ atingiu uma atividade lipolítica máxima de 94,88 $\mathrm{U} \mathrm{g} \mathrm{g}^{-1} \mathrm{e}$ aeração de $60 \mathrm{~mL} \mathrm{~g}^{-1} \mathrm{~h}^{-1}$ obteve 84,98 $\mathrm{U} \mathrm{g}^{-1}$ de atividade. Uma melhor adaptação do Aspergillus fumigatus no meio com óleo diesel já era esperada, pois este microrganismo foi isolado de um local contaminado com hidrocarbonetos.

Para o óleo de soja, tanto o Aspergillus fumigatus quanto o Phialemonium sp. apresentaram resultados expressivos, quando o meio utilizado continha farelo e casca de arroz, sendo que apresentaram atividade lipolítica cerca de $20 \%$ maior com a taxa de aeração em 60 $\mathrm{mL} \mathrm{g}^{-1} \mathrm{~h}^{-1}$, quando comparado com a aeração de $120 \mathrm{~mL} \mathrm{~g}^{-1} \mathrm{~h}^{-1}$.

O meio fermentativo sem fonte adicional de carbono obteve como melhor resposta para produção de lipase o fungo Aspergillus fumigatus, no suporte complexo, independente da taxa de aeração, pois a variação entre as mesmas foi muito pequena, 105,34 e 98,35 $\mathrm{U} \mathrm{g}^{-1}$, para as taxas de aeração de 60 e $120 \mathrm{~mL} \mathrm{~g}^{-1} \mathrm{~h}^{-1}$, respectivamente. Pesquisas anteriores sobre a fisiologia da produção de lipases mostraram que os mecanismos que regularizam a biossíntese variam amplamente em diferentes microrganismos. Produção de lipase a partir de Rhizopus, ${ }^{29}$ Rhodotorula ${ }^{30}$ e Aspergillus ${ }^{5}$ pode ser constitutiva e independente da adição de substratos lipídicos ao meio de fermentação.

O suporte sintético não apresentou características adequadas para a produção de lipase durante o processo fermentativo de produção de biossurfactante, pois este forneceu baixos índices de atividade lipolítica quando comparados aos encontrados para o suporte complexo sob as mesmas condições. Outro fator que provavelmente afetou a produção de lipase no meio inerte foi a aeração, pois foi observado que a partir de $96 \mathrm{~h}$ a umidade do meio diminuiu rapidamente.

Foi verificado que praticamente todos os experimentos apresentaram uma queda na atividade lipolítica ao final da fermentação. Segundo pesquisadores, isto ocorre devido à liberação de proteases no meio durante o processo fermentativo; as proteases hidrolisam uma parte das lipases produzidas. ${ }^{24,31,32}$ Rivera-Munöz et al ${ }^{32}$ observaram que os melhores microrganismos produtores de lipases são produtores intermediários de proteases. Este fato sugere que a atividade proteolítica talvez afete a estabilidade da atividade lipolítica.

$\mathrm{Na}$ Tabela 3 estão expostos os efeitos principais para todas variáveis estudadas e as respectivas interações nos biorreatores de coluna.

O microrganismo, o suporte e a fonte de carbono linear apresentaram diferença significativa em nível de 5\%. Além destes, as interações 

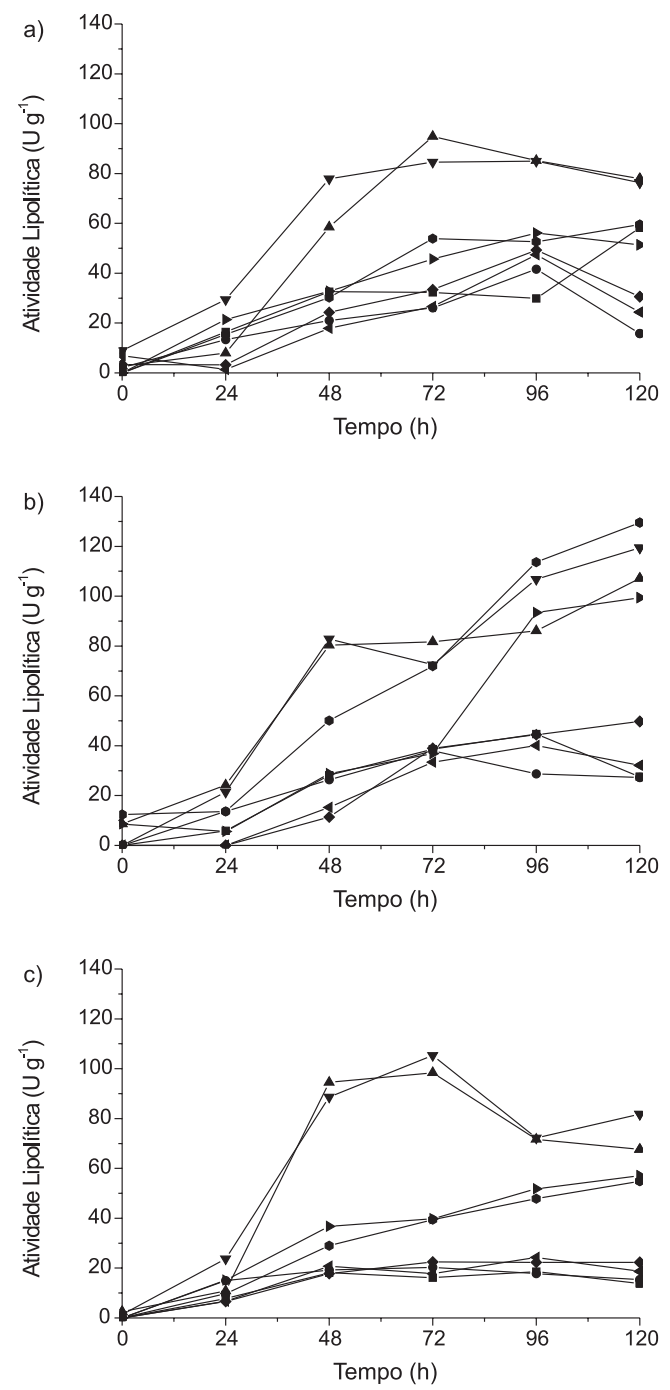

Figura 1. Produção de lipase durante o processo de fermentação em biorreatores de coluna. (a) óleo diesel; (b) óleo de soja e (c) sem fonte de carbono

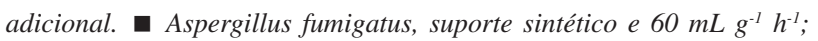
Aspergillus fumigatus, suporte sintético e $120 \mathrm{~mL}^{-1} \mathrm{~h}^{-1}$; $\mathbf{\Delta}$ Aspergillus fumigatus, suporte complexo e $120 \mathrm{~mL} \mathrm{~g}^{-1} \mathrm{~h}^{-1}$; $\boldsymbol{\nabla}$ Aspergillus fumigatus, suporte complexo e $60 \mathrm{~mL} \mathrm{~g}^{-1} \mathrm{~h}^{-1}$; Phialemonium sp., suporte sintético e $60 \mathrm{~mL} \mathrm{\textrm {g } ^ { - 1 }}$ $h^{-1} ;+$ Phialemonium sp., suporte sintético e $120 \mathrm{~mL} \mathrm{~g}^{-1} h^{-1} ; \times$ Phialemonium sp., suporte complexo e $120 \mathrm{~mL} \mathrm{~g}^{-1} h^{-1}$ e $*$ Phialemonium sp., suporte complexo e $60 \mathrm{~mL} \mathrm{~g}^{-1} \mathrm{~h}^{-1}$

do fungo com o suporte, fungo com a fonte de carbono linear e o suporte com a fonte de carbono quadrática também apresentaram diferença significativa em um intervalo de confiança de $95 \%$.

Quando o microrganismo passou do nível inferior para o superior, a atividade lipolítica diminuiu 11,82 $\mathrm{U} \mathrm{g}^{-1}$. A mesma apresentou um aumento de 50,99 $\mathrm{U} \mathrm{g}^{-1}$ quando o suporte complexo substituiu o sintético. A diferença entre o meio adicionado de óleo de soja e o sem fonte adicional de carbono também foi significativa $(\mathrm{p}<0,05)$, mostrando que quando o óleo de soja não estava presente no meio a atividade lipolítica diminuiu $28,32 \mathrm{U} \mathrm{g}^{-1}$. A aeração não teve influência significativa em nível de 5\%, mas começou a apresentar diferença significativa em um intervalo de confiança de $82 \%$.

Vários autores relataram que a aeração, em alguns casos, é essencial para que os microrganismos produzam lipase. ${ }^{33}$ Lee e Rhee ${ }^{34}$ conseguiram aumentar a produção de lipase a partir da bactéria $\mathrm{Pseu}$ domonas putida sob condições distintas de aeração e agitação. Elibol
Tabela 3. Efeitos das variáveis do planejamento experimental na atividade lipolítica máxima de cada experimento nos biorreatores de coluna

\begin{tabular}{lcc}
\hline & Atividade Lipolítica $\left(\mathrm{U} \mathrm{g}^{-1}\right)$ & $p$ \\
\hline Média/Interações & 63,38 & 0,000 \\
(1) Fungo (L) & $-11,82$ & 0,019 \\
(2) Suporte (L) & 50,99 & 0,000 \\
(3) Aeração (L) & $-5,99$ & 0,182 \\
(4) Carbono (L) & $-28,32$ & 0,000 \\
Carbono (Q) & $-2,83$ & 0,535 \\
1L x 2L & $-13,79$ & 0,008 \\
1L x 3L & $-0,82$ & 0,847 \\
1L x 4L & $-11,66$ & 0,047 \\
1L x 4Q & $-3,77$ & 0,413 \\
2L x 3L & $-0,78$ & 0,854 \\
2L x 4L & $-6,62$ & 0,225 \\
2L x 4Q & $-19,68$ & 0,001 \\
3L x 4L & 7,19 & 0,190 \\
3L x 4Q & 2,27 & 0,618 \\
\hline
\end{tabular}

$\mathrm{L}=$ efeito linear; $\mathrm{Q}=$ efeito quadrático; $p=$ nível de significância.

e Ozer ${ }^{3}$ obtiveram aumento da produtividade da lipase produzida pelo fungo Rhizopus arrhizus aumentando a taxa de aeração.

As interações dos microrganismos com os suportes utilizados, dos microrganismos com as fontes de carbono e dos suportes com as fontes de carbono quadráticas fizeram com que a atividade lipolítica diminuísse 13,79; 11,66 e 19,68 U g ${ }^{-1}$, respectivamente.

A Tabela 4 apresenta os resultados da atividade lipolítica para o planejamento experimental misto $2^{2} \times 3$, utilizado para avaliar a produção de lipase nos erlenmeyers. A análise do planejamento foi realizada para um nível de significância de 5\% utilizando os resultados de atividade lipolítica máxima para cada um dos experimentos.

A umidade e o pH dos meios mantiveram-se praticamente estáveis ao longo das fermentações, mesmo nos experimentos contendo somente o suporte sintético, sendo que a umidade permaneceu em $50 \pm 3 \%$ e o $\mathrm{pH}$ em 5,0 \pm 0,5 para os ensaios realizados com o Aspergillus fumigatus e 4,5 $\pm 0,5$ para o Phialemonium sp.. Mahadik et $a l .{ }^{28}$ estudaram a produção de lipase a partir de farelo de trigo com o fungo Aspergillus niger e verificaram que a máxima produção da

Tabela 4. Resultados do planejamento experimental $2^{2} \times 3$ para o estudo da produção da lipase nos erlenmeyers

\begin{tabular}{lcccc}
\hline Experimentos & $\mathrm{X}_{1}$ & $\mathrm{X}_{2}$ & $\mathrm{X}_{3}$ & $\begin{array}{c}\text { Atividade } \\
\text { Lipolítica }\left(\mathrm{U} \mathrm{g}^{-1}\right)\end{array}$ \\
\hline 1 & -1 & -1 & -1 & 42,05 \\
2 & 1 & -1 & -1 & 48,74 \\
3 & -1 & 1 & -1 & 100,61 \\
4 & 1 & 1 & -1 & 93,18 \\
5 & -1 & -1 & 0 & 53,85 \\
6 & 1 & -1 & 0 & 70,95 \\
7 & -1 & 1 & 0 & 105,70 \\
8 & 1 & 1 & 0 & 131,92 \\
9 & -1 & -1 & 1 & 66,64 \\
10 & 1 & -1 & 1 & 42,03 \\
11 & -1 & 1 & 1 & 94,11 \\
12 & 1 & 1 & 1 & 94,94 \\
\hline
\end{tabular}

$\mathrm{X}_{1}=$ fungo; $\mathrm{X}_{2}=$ meio fermentativo; $\mathrm{X}_{3}=$ fonte de carbono. 
enzima foi obtida quando o farelo de trigo foi umedecido com uma relação de 1:2,5 (substrato:solução); quando a taxa utilizada foi de 1:1 a atividade lipolítica diminuiu cerca de 10 vezes.

A produção de lipase nos erlenmeyers, assim como nas fermentações realizadas nas colunas não apresentou relação com a produção de biossurfactante. Para o fungo Aspergillus fumigatus, a máxima atividade lipolítica observada foi $105,70 \mathrm{U} \mathrm{g}^{-1}$, quando utilizado o suporte complexo e óleo diesel como fonte de carbono adicional. Neste experimento, as atividades emulsificantes encontradas foram de 12,33 UE $\mathrm{g}^{-1}$ para óleo/água e 6,38 $\mathrm{UE} \mathrm{g}^{-1}$ para água/óleo. A atividade lipolítica máxima encontrada para o fungo Phialemonium sp. foi $131,92 \mathrm{U} \mathrm{g}^{-1}$, utilizando o suporte complexo e óleo diesel como fonte de carbono adicional. As atividades emulsificantes observadas neste caso foram 9,55 UE g ${ }^{-1}$ para óleo/água e 5,16 UE g ${ }^{-1}$ para água/óleo.

Na Tabela 5 são apresentados os efeitos principais para todas variáveis estudadas e as respectivas interações nos experimentos utilizando erlenmeyers.

Tabela 5. Efeitos das variáveis do planejamento experimental na atividade lipolítica máxima de cada experimento nos erlenmeyers

\begin{tabular}{lcc}
\hline & Atividade Lipolítica $\left(\mathrm{U} \mathrm{g}^{-1}\right)$ & $p$ \\
\hline Média/Interações & 78,76 & 0,001 \\
(1) Fungo (L) & 3,05 & 0,643 \\
(2) Suporte (L) & 49,29 & 0,012 \\
(3) Carbono (L) & 3,17 & 0,692 \\
Carbono (Q) & 17,76 & 0,098 \\
1L por 2L & 3,48 & 0,601 \\
1L por 3L & $-5,64$ & 0,501 \\
1L por 3Q & 13,95 & 0,146 \\
2L por 3L & $-5,54$ & 0,508 \\
2L por 3Q & 5,33 & 0,468 \\
\hline
\end{tabular}

$\mathrm{L}=$ efeito linear; $\mathrm{Q}=$ efeito quadrático; $p=$ nível de significância.

Foi observado que apenas o suporte apresentou diferença significativa em nível de significância de 5\%. A atividade lipolítica obteve um aumento de 49,29 $\mathrm{U} \mathrm{g}^{-1}$ quando o suporte sintético foi substituído pelo complexo. A variável fonte de carbono quadrática foi significativa, mostrando que quando o óleo diesel estava presente no meio a atividade lipolítica aumentou $17,76 \mathrm{U} \mathrm{g}^{-1}$.

A Figura 2 apresenta a cinética da produção de lipase para cada uma das fontes de carbono estudadas durante $120 \mathrm{~h}$ de fermentação.

Foi verificado que utilizando óleo diesel, Phialemonium sp. e suporte complexo a atividade lipolítica alcançou 131,92 U g-1 , cerca de $25 \%$ a mais que com Aspergillus fumigatus sob as mesmas condições. O Aspergillus fumigatus na presença de óleo de soja com o suporte complexo atingiu 100,61 $\mathrm{U} \mathrm{g}^{-1}$, enquanto que o Phialemonium sp. apresentou cerca de $30 \%$ a menos de atividade quando comparado ao meio que continha óleo diesel.

No meio fermentativo sem fonte de carbono adicional, os melhores resultados foram obtidos para o suporte complexo e para ambos os fungos, pois apresentaram atividades lipolíticas máximas em torno de $94 \mathrm{U} \mathrm{g}^{-1}$. As fontes de carbono lipídicas parecem ser essenciais para a obtenção de altas produções de lipase, sendo que alguns autores têm conseguido produções razoáveis na ausência de óleos e gorduras. ${ }^{35}$

Em praticamente todos os experimentos, assim como nos biorreatores de coluna, foi observada uma diminuição da atividade lipolítica ao término da fermentação; isto se deve ao fato de que, provavelmente, as proteases liberadas no meio hidrolisaram as lipases produzidas.

As lipases produzidas durante o processo fermentativo apresentadas neste estudo, além de poderem ser aplicadas no processo de
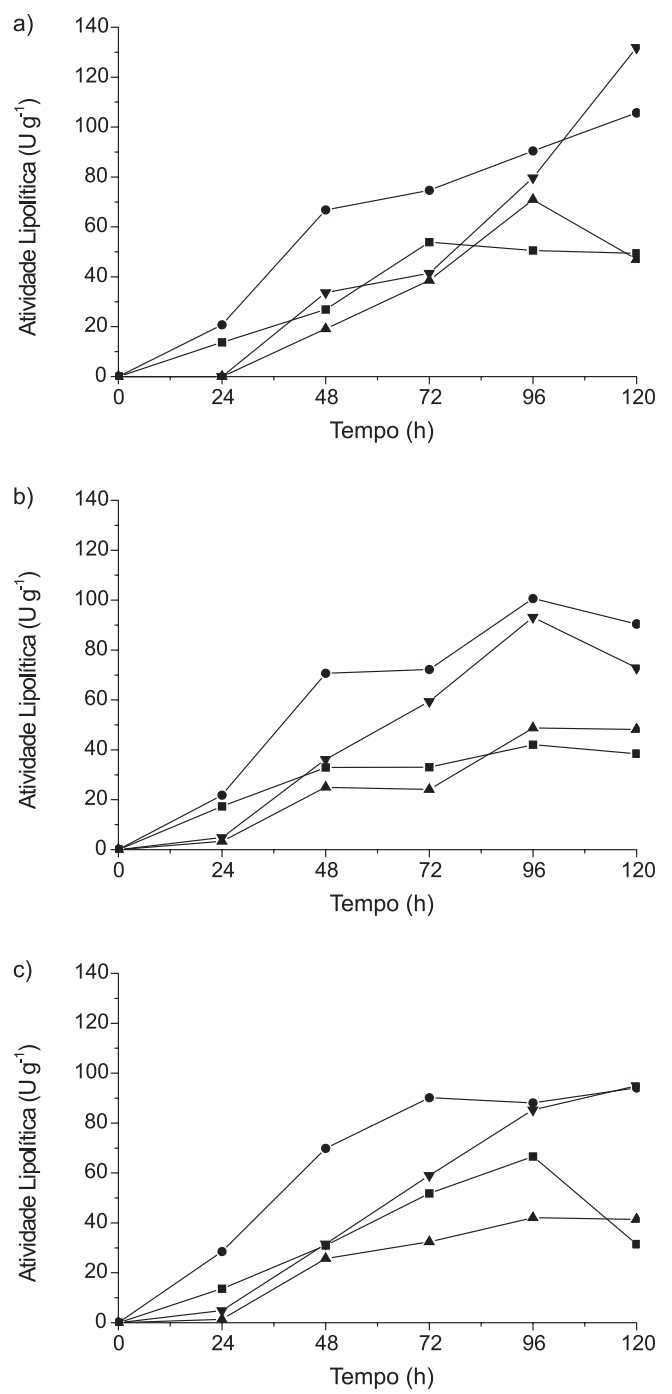

Figura 2. Produção de lipase durante o processo de fermentação nos erlenmeyers. (a) óleo diesel; (b) óleo de soja e (c) sem fonte de carbono adicional. - Aspergillus fumigatus e suporte sintético; - Aspergillus fumigatus e suporte complexo; $\mathbf{\Delta}$ Phialemonium sp. e suporte sintético; $\boldsymbol{\nabla}$ Phialemonium sp. $e$ suporte complexo

biorremediação juntamente com o biossurfactante, também possuem aplicações em indústrias de detergentes, oleoquímica, tratamento de efluentes, entre outras.

\section{CONCLUSÃO}

A quantidade de lipase gerada no meio fermentativo não interferiu na produção de biossurfactante, em nenhum dos biorreatores avaliados, o que pode ser interessante em uma futura aplicação deste meio em uma biorremediação, pois a lipase aceleraria este processo. $\mathrm{Na}$ literatura não foi encontrada nenhuma referência de produção de lipase com os fungos utilizados neste estudo e com aplicação em processo de biorremediação. Dentre as condições estudadas, para produzir lipase a mais adequada seria utilizar o fungo Phialemonium sp. juntamente com o suporte complexo adicionado de óleo diesel.

A metodologia aplicada utilizando resíduos agroindustriais mostrou ser eficiente para a produção de lipase, porém os reatores aerados quando utilizados com o meio sintético não se mostraram adequados, já que a umidade diminuiu a um nível que prejudicou a produção de lipase. 
Os hidrocarbonetos têm sido relatados como substratos potenciais para a produção microbiana de várias enzimas e metabólitos secundários, o que pode ser verificado, pois o Phialemonium sp. em suporte complexo contendo óleo diesel alcançou atividade lipolítica de $131,92 \mathrm{U} \mathrm{g}^{-1}$, porém a utilização destes substratos para a produção de lipases não tem recebido a atenção adequada, o que é revelado pela literatura limitada sobre este assunto.

As enzimas lipolíticas têm atraído cada vez mais atenção por causa do seu potencial biotecnológico. Estas constituem o grupo mais importante de biocatalisadores para aplicações biotecnológicas. As razões do enorme potencial dessa enzima incluem fatos relacionados com a alta estabilidade em solventes orgânicos, não requerem a presença de co-fatores, possuem uma larga especificidade pelo substrato e exibem uma alta enantiosseletividade.

\section{AGRADECIMENTOS}

Ao suporte financeiro do Conselho Nacional de Desenvolvimento Científico e Tecnológico (CNPq) e à Indústria Riograndense de Óleos Vegetais Ltda que forneceu a casca e o farelo de arroz desengordurado, que viabilizaram o desenvolvimento do trabalho.

\section{REFERÊNCIAS}

1. Diaz, J. C. M.; Rodríguez, J. A.; Roussos, S.; Cordova, J.; Abousalham, A.; Carriere, F.; Enzyme Microb. Technol. 2006, 39, 1042.

2. Cammarota, M. C.; Freire, D. M. G.; Bioresour. Technol. 2006, 97, 2195.

3. Elibol, M.; Ozer, D.; Process Biochem. 2000, 36, 325.

4. Long, K.; Ghazali, H. M.; Ariff, A.; Ampon, K.; Bucke, C.; J. Chem. Technol. Biotechnol. 1996, 67, 157.

5. Pokorny, D.; Friedrich, J.; Cimerman, A.; Biotechnol. Lett. 1994, 16, 363.

6. Li, C. Y.; Cheng, C. Y.; Chen, T. L.; Biochem. Eng. J. 2004, 19, 25.

7. Muralidhar, R. V.; Chirumamila, R. R.; Marchant, R.; Nigam, P.; Biochem. Eng. J. 2001, 9, 17.

8. Nahas, E.; J. Gen. Microbiol. 1995, 134, 227.

9. Santoyo, A. B.; Rodríguez, J. B.; Martín, M. F. M.; Morte, M. C. M.; Membrillera, G. V. G.; Requena, S. O.; J. Biotechnol. 2007, 131, S82.

10. Tarassuk, N. P.; Frankil, E. N.; J. Dairy Sci. 2007, 40, 418.
11. Hansa, F.; Shah, A. A.; Hameed, A.; Enzyme Microb. Technol. 2006, 39, 235 .

12. Galante, Y. M.; Formantici, C.; Curr. Org. Chem. 2003, 7, 1399.

13. Paques, F. W.; Macedo, G. A.; Quim. Nova 2006, 29, 93.

14. Carvalho, P. O.; Calafatti, S. A.; Marassi, M.; Silva, D. M.; Conteseni, F. J.; Bizaco, R.; Macedo, G. A .; Quim. Nova 2005, 28, 614.

15. Mendes, A. A.; Castro, H. F.; Pereira, E. B.; Furigo Jr., A.; Quim. Nova 2005, 28, 296.

16. Marten, E.; Muller, R. J.; Deckwer, W. D.; Polym. Degrad. Stab. 2003, 80,485 .

17. Rosenberg, E.; Trends Biotechnol. 1993, 11, 419.

18. Singh, P.; Cameotra, S. S.; Trends Biotechnol. 2004, 22, 142.

19. Makkar, R. S.; Cameotra, S. S.; Appl. Microbiol. Biotechnol. 2002, 58, 428.

20. Makkar, R. S.; Cameotra, S. C.; J. Surfactants Deterg. 1999, 2, 237.

21. Martins, V. G.; Kalil, S. J.; Bertolin, T. E.; Costa, J. A. V.; Z. Naturforsch, C: J. Biosci. 2006, 61, 721.

22. Costa, J. A. V.; Alegre, R. M.; Hasan, S. D. M.; Biotechnol. Technol. 1998, $12,747$.

23. AOAC; Official Methods of Analysis of International, $16^{\text {th }}$ ed., Arlington, 1995.

24. Burkert, J. F. M.; Maugeri, F.; Rodrigues, M. I.; Bioresour. Technol. 2004, 91, 77.

25. Johnson, V.; Singh, M.; Saini, V. S.; Biotechnol. Lett. 1992, 14, 487.

26. Broderick, L. S.; Cooney, J. J.; Dev. Ind. Microbiol. 1982, 23, 425.

27. Pokorny, D.; Cimerman, A.; Steiner, W.; J. Mol. Catal. B. Enzym. 1997, $2,215$.

28. Mahadik, N. D.; Puntambekar, U. S.; Bastawde, K. B.; Khire, J. M.; Gokhale, D. V.; Process Biochem. 2002, 38, 715.

29. Salleh, A. B.; Musani, R.; Basri, M.; Ampon, K.; Yunus, W. M. Z.; Razak, C. N. A.; Can. J. Microbiol. 1993, 39, 978.

30. Papaparaskevas, D.; Christakopoulos, P.; Kekos, D.; Macris, B. J.; Biotechnol. Lett. 1992, 14, 397

31. Ohnishi, K.; Yoshida, Y.; Sekiguchi, J.; J. Ferment. Bioeng. 1994, 77, 490.

32. Rivera-Munöz, G.; Tinoco-Valencia, J. R.; Sánchez, S.; Farrés, A.; Biotechnol. Lett. 1991, 13, 277.

33. Vadehra, D. A.; Harmon, L. G.; J. Appl. Bacteriol. 1969, 32, 147.

34. Lee, S. Y.; Rhee, J. S.; Enzyme Microb. Technol. 1993, 15, 617.

35. Sharma, R.; Christi, Y.; Banerjee, U. C.; Biotechnol. Adv. 2001, 19, 627. 